Volume 8(3), 81-100. https://doi.org/10.18608/jla.2021.7379

\title{
More Than Figures on Your Laptop: (Dis)trustful Implementation of Learning Analytics
}

\author{
Yi-Shan Tsai ${ }^{1}$, Alexander Whitelock-Wainwright ${ }^{2}$, Dragan Gašević ${ }^{3}$
}

\begin{abstract}
The adoption of learning analytics (LA) in complex educational systems is woven into sociocultural and technical challenges that have induced distrust in data and difficulties in scaling LA. This paper presents a study that investigated areas of distrust and threats to trustworthy LA through a series of consultations with teaching staff and students at a large UK university. Surveys and focus groups were conducted to explore participant expectations of LA. The observed distrust is broadly attributed to three areas: the subjective nature of numbers, the fear of power diminution, and approaches to design and implementation of LA. The paper highlights areas to maintain existing trust with policy procedures and areas to cultivate trust by engaging with tensions arising from the social process of LA.
\end{abstract}

\footnotetext{
Notes for Practice and Research

- Learning analytics (LA) is about human decisions, which need to be carefully inspected, justified, and even challenged to serve the purpose of enhancing learning.

- LA is about reflecting on factors that contribute to observed patterns and prompting actions as a result.

- LA is about the social process in which power is negotiated as data flows.
}

\section{Keywords}

Learning analytics, trust, institutional adoption, human-computer interaction, datafication

Submitted: 07/10/2020 - Accepted: 14/07/2021 — Published: 13/10/2021

Corresponding author ${ }^{1}$ Email: yi-shan.tsai@monash.edu Address: Faculty of Information Technology, Monash University, Melbourne, Australia. ORCID ID: https://orcid.org/0000-0001-8967-5327

${ }^{2}$ Email: alex.wainwright@monash.edu Address: Office of the VC \& President, Monash University, Melbourne, Australia. ORCID ID: https://orcid.org/ 0000-0003-3033-4629

${ }^{3}$ Email: dragan.gasevic@monash.edu Address: Faculty of Information Technology, Monash University, Melbourne, Australia. ORCID ID: https://orcid.org/0000-0001-9265-1908

\section{Introduction}

Learning analytics (LA) has much appeal to many higher-education institutions seeking to address some of their most pressing challenges (Gašević, Kovanović, \& Joksimović, 2017). This appeal comes from several perspectives, including, but not limited to, financial incentives, education quality, and social responsibility. Some of the most prominent examples of the use of learning analytics in higher education have been related to early identification of students at risk and personalized feedback at scale (Herodotou, Rienties, Boroowa, Zdrahal, \& Hlosta, 2019; Pardo, Jovanovic, Dawson, Gašević, \& Mirriahi, 2019). Reports about the positive impact of these applications of LA have attracted much attention from many institutions around the world and led them to invest in relevant institutional projects. However, in spite of this interest, the literature indicates that LA is still in the early stages of adoption in many higher-education institutions (Tsai, Rates, et al., 2020).

The literature has identified several barriers to the adoption of LA in higher education. The systematic review by Tsai and Gašević (2017) highlights several reasons for the limited adoption of LA in higher education, including a shortage of academic leadership for strategic implementation and monitoring, unequal engagement between different stakeholder groups, underdeveloped capabilities for data-informed decision making, and a lack of policies for LA practice. In recent years, some progress has been made, and most of these concerns have been addressed to some extent by emphasizing primary stakeholder involvement in co-designing LA (Dollinger, Liu, Arthars, \& Lodge, 2019) and building frameworks for developing institutional 
policies and strategies (Tsai et al., 2018; Gašević, Tsai, Dawson, \& Pardo, 2019). However, while relevant conceptual debates date back to the early days of LA (Pardo \& Siemens, 2014; Ferguson, 2012; Ferguson, Hoel, Scheffel, \& Drachsler, 2016), empirical research on barriers to the adoption of LA by primary stakeholders (i.e., students and teaching staff) is relatively new and scarce.

Trust can be a significant barrier to the adoption of LA. While privacy and ethics have been common topics, trust has only recently attracted attention in the LA literature (Jones et al., 2020; Jones, Rubel, \& LeClere, 2019), focusing on either students or teaching staff (Jones et al., 2020; Tsai, Whitelock-Wainwright, \& Gašević, 2020; Slade, Prinsloo, \& Khalil, 2019; Klein, Lester, Rangwala, \& Johri, 2019). The emerging literature suggests that students generally trust institutions to collect and use their data (Tsai, Whitelock-Wainwright, \& Gašević, 2020; Slade et al., 2019). They would, however, like to see improvements in transparency about the ways data about them is used by institutions for LA (Tsai, Whitelock-Wainwright, \& Gašević, 2020; Slade et al., 2019). Views on trust among teaching staff tend to be shaped by the institutional context and commitment (Klein et al., 2019). While existing studies offer valuable insights that can inform adoption of LA, few studies compare student and teaching staff perspectives on trust within the context of a single institution. The literature recognizes the significance of the unique context of each higher-education institution on LA adoption (Tsai et al., 2018; Klein et al., 2019; Selwyn, 2019). The shared experience among stakeholders from the same institution (e.g., institutional culture, learning, and teaching practices and other relevant social, economic, and technological factors) can provide important insights for strategy formation by comparing multi-stakeholder attitudes, lived experiences, and expectations of LA.

To fill the above-mentioned gaps in the literature on trust in LA, this paper reports on the findings of a study that addressed the following two research questions: (1) "In what areas do students and teachers trust or distrust the university to implement LA?" and (2) "What are the threats to trustworthy implementation of LA?" The study used mixed methods (survey and focus groups) and involved students and teaching staff of a large research-intensive university in the UK.

\section{Literature Review}

LA comprises a plethora of interdisciplinary fields primarily driven by theories and practices of data science, education, and psychology. Essentially, LA seeks to support learning by providing data-driven feedback that may inform decisions related to learning strategies, instructional design, and institutional management. Gašević and colleagues (2017) suggest that LA as a field aims to "harness unprecedented amounts of data collected by the extensive use of technology in education" (p. 63). As such, common methods used to distill and visualize information include predictive modelling, clustering analysis, network analysis, text mining, and process and sequence mining (Viberg, Hatakka, Bälter, \& Mavroudi, 2018; Leitner, Khalil, \& Ebner, 2017; Dawson, Joksimovic, Poquet, \& Siemens, 2019; Matcha, Gašević, Uzir, Jovanović, \& Pardo, 2019). Although research in the field has shown promising results in enhancing our understanding of learning, particularly how behaviours (e.g., time management, learning strategies, interactions with feedback and learning material, and learning collaboration) relate to learning outcomes, there is consistent evidence of resistance to LA as a result of a mix of political, social, cultural, and technical norms (Macfadyen, Dawson, Pardo, \& Gašević, 2014; Tsai, Poquet, Dawson, Pardo, \& Gašević, 2019; Arnold, Lonn, \& Pistilli, 2014; Oster, Lonn, Pistilli, \& Brown, 2016; Tsai, Perrotta, \& Gašević, 2019; Roberts, Howell, Seaman, \& Gibson, 2016; Howell, Roberts, Seaman, \& Gibson, 2018). The values and beliefs held by individuals shape people's perceptions and interpretations of data (Prinsloo, Slade, \& Khalil, 2018), their motivations to engage with data, and their inclination to act on information derived from data. In other words, LA adoption is a delicate matter of trust. As an example, an eight-point checklist named DELICATE was proposed by Drachsler and Greller (2016) to promote trust in LA. Aligning human values with the use of data in education is a paramount step in the scaling of LA (Chen \& Zhu, 2019). In this section, we explore important issues related to trust in the field of LA and review existing approaches to trustworthy LA.

\subsection{Trust Issues with Learning Analytics}

[D] ata are political in nature-loaded with values, interests and assumptions that shape and limit what is done with it and by whom. (Selwyn, 2015, p. 69)

Data analytics seeks to uncover hidden patterns, trends, and correlations by applying complex computational methods to examine large, varied data sets. While the large volume of data collected appears to allow more objective approaches to understanding learning and learners, various choices made, from selecting data sources and measurement metrics to interpreting data and deciding interventions, are subject to human beliefs and assumptions. Selwyn (2015) thus argues that data processing is a powerful social practice in which people are classified, sorted, ordered, and ranked. This process perpetuates problems of compromises, biases, and omissions that may or may not be made known to those who make decisions or to those for/about whom decisions are made. The emergence of LA is an example of how data practice is shaped by social interests. A growing 
trend of marketization in the educational sector has placed undue pressure on higher-education institutions to provide evidence to demonstrate quality and excellence to funding bodies and the public (Ferguson, 2012). As a result, drivers for institutional adoption of LA often focus on enhancing performance according to quality metrics, including teaching quality, student outcome and learning gain, student satisfaction, graduate employment, and international reputation (Tsai, Rates, et al., 2020). The political agendas behind institutional interest in LA have led to critiques of a utopian vision of a smart university that encodes the objectives of various actors in policy networks (e.g., think tanks, political and private sectors) into the technical infrastructure in higher education (Williamson, 2018). The disposition of data processing as a social and political activity has drawn attention to conflicts that occur in the differences between value systems and the unequal distribution of power in society. LA thus suffers from trust issues that can be broadly attributed to two issues: the subjectivity of numbers and the fear of power diminution.

Issue 1: Numbers are subjective Insights obtained from LA are objective to the extent that the reliability of observed patterns can be enhanced by a sample that is large in volume and diverse in scope. However, the "data exhaust" used in learning analytics is associated with several issues. Data requires significant work on pre-processing and transformations to make it suitable for analysis (Slade \& Prinsloo, 2013). The issue associated with this is that data coming from different sources is not standardized and can be hard to link semantically (Jovanovic et al., 2007). Data is also highly dimensional, which requires significant efforts by data analysts to identify relevant variables and features. Due to these issues, several subjective choices made by developers, researchers, and downstream users can affect how and what information is presented to educators and students. In terms of choices of data, LA systems are found to rely on trace data in addition to other common data sources used in educational sectors, e.g., assessment, student information, and survey (Tsai, Rates, et al., 2020). Although there is much promise in the use of trace data to understand learning processes and predict success (Gašević et al., 2019), researchers have cautioned that the behaviourist approach may lead to a performative culture (Brown, 2020; Knox, 2017; Williamson, Bayne, \& Shay, 2020; Wintrup, 2017). The awareness of being observed can prompt students (and educators) to consciously or unconsciously produce behaviour that "satisfies" algorithms. For example, it has been reported that students deliberately produce fake attendance data knowing they are being tracked (Brown, 2020) or indicate that they would have behaved differently had they known that their course interactions were being recorded (Knox, 2017). This has induced distrust in data among educators and concerns that the desire to learn would be "diluted" when knowledge building is based on preemptive behaviour, especially when predictive analytics are applied (Wintrup, 2017; Selwyn, 2015). In addition, distrust in LA is observed in relation to a data-driven approach, i.e., sourcing data based on what can be observed and easily captured (Howell et al., 2018). Concerns about restricting interpretations of learning have led to a call for question-driven approaches and creative data sourcing based on principles established in educational research and practice (Gašević et al., 2019). The importance of aligning LA with the purpose of education, e.g., to drive societal growth and transformation, has also been voiced by experts in the LA field (Ferguson, Clow, Griffiths, \& Brasher, 2019) and discussed as a related issue to "algorithmic accountability" (Hakami \& Hernández-Leo, 2020).

Related to data sourcing are choices of indicators used to measure and infer learning. While researchers have frequently highlighted the need to identify meaningful indicators according to learning design (Chen \& Zhu, 2019; Gašević, Dawson, \& Siemens, 2015; Lodge \& Corrin, 2017), LA continues to face criticism of its reductionist approach to describing learners using quantitative categories (Williamson et al., 2020). For example, several researchers caution that LA miscounts learning engagement that happens at spaces and times outside of direct interaction with class activities (Knox, 2017; Roberts et al., 2016; Prinsloo \& Slade, 2016; Ifenthaler \& Schumacher, 2016). In a similar vein, Brown (2020) warns that LA dashboards can limit how educators "see" students, Lodge and Lewis (2012) contend that how students interact with information is more important than "how much," and Selwyn (2020) argues that those who do not fit neatly into discrete categories can potentially face incorrect diagnosis of their learning progress and unfair treatment. The latter in particular has raised concerns about equity and justice in the educational context. It has been argued that algorithms can enable digital discrimination in a relentless process of classification and categorization for the purpose of inclusion or exclusion (Norris \& Lyon, 2003). This social sorting process focuses on who belongs to a group over why people do not belong or whether the group is exclusionary by default. Along the lines of concern about technology-assisted learning being increasingly positioned as a self-centred endeavour (Castañeda \& Selwyn, 2018), LA has raised apprehension about representing learners in a decontextualized manner, discounting structural issues that have contributed to how students are being labelled and represented with numbers (Selwyn, 2015; Selwyn \& Gašević, 2020). Within the field of LA, awareness of fairness and student well-being is rising, though more effort is required to address these issues (Hakami \& Hernández-Leo, 2020).

Issue 2: Fear of power diminution Distrust in LA arguably derives from a fear of power diminution. Data extraction is considered a one-way process, and it can be perceived as a form of control when its purpose is to predict and modify human behaviour (Zuboff, 2015). Several issues associated with surveillance and autonomy have thus raised concerns regarding practice that is contradictory to educational values. For example, Rubel and Jones (2016) contend that massive and constant data 
collection for LA threatens student agency, which conflicts with the values upheld by higher education. Similarly, Kwet and Prinsloo (2020) argue that smart campus projects normalize surveillance that violates the rights of individuals and potentially causes chilling effects among students. Moreover, some personalized approaches, such as nudging and prescribing, have raised concerns among staff about spoon-feeding rather than empowering students (Tsai, Perrotta, \& Gašević, 2019). Knox (2017, p. 749) argues further, "if LA prediction were to become truly flawless, it would be able to account for any 'response' or 'action,' thereby exonerating students, teachers, and institutions from any responsibility for educational success, or lack of it." While LA is intended to empower learners by leveraging their decision making with data about their learning, variations in personal beliefs and approaches to learning can lead to perceptions of LA as being either supportive or controlling (Selwyn, 2020; Roberts et al., 2016; Schumacher \& Ifenthaler, 2018). Also, academic staff are averse to the potential loss of academic autonomy when LA is used to judge teaching performance (Kwet \& Prinsloo, 2020; Selwyn, 2020) or conform teaching strategies to allow certain types of data to be used as parameters to measure learning (Brown, 2020). Although the purpose of LA is not to track but to empower learners and educators (Selwyn \& Gašević, 2020), the means to the goals of understanding and optimizing learning and learning environments (Long, Siemens, Conole, \& Gašević, 2011) may appear to be hostile and therefore in need of control in order to fulfill an institution's fiduciary responsibility (Jones et al., 2019).

The issue with power diminution in terms of the scope of autonomy in decision making for teachers and students can be worsened by imbalanced power relationships in an institutional structure. For example, studies have shown that students have insufficient understanding of who has access to their data, what has been done to it, and the consequences of sharing it (Tsai, Whitelock-Wainwright, \& Gašević, 2020; Jones et al., 2020). It has been argued that the scale of data collection, issues with re-identification in data aggregation, and timing of consent-seeking make informed consent problematic due to "bounded rationality" (rationality of individuals in decision making is limited by the information they posses) (Prinsloo \& Slade, 2015). Similarly, the difficulty of comprehending algorithmic complexity can place staff in a powerless position when it comes to interpreting LA-based feedback and devising interventions (Tsai, Perrotta, \& Gašević, 2019). As mentioned earlier, data collection is a one-way process between the collector and the data subject. The increasing data flow between different stakeholders in an institution and with external service providers has arguably perpetuated existing and new asymmetrical power relations (Kwet \& Prinsloo, 2020). The issue of power distribution among different stakeholders in an educational environment is an important aspect to consider when defining data control, stakeholder responsibility, and accountability (Lang, Macfadyen, Slade, Prinsloo, \& Sclater, 2018; Hakami \& Hernández-Leo, 2020).

\subsection{Cultivating Trust with Inclusive Approaches}

Creating a shared vision for LA requires a thoughtful alignment of values and priorities held by different stakeholders. Studies have thus called for a more inclusive strategy for adopting LA, particularly the involvement of teachers and students (Vigentini, Liu, Arthars, \& Dollinger, 2020; Tsai, Rates, et al., 2020; Roberts et al., 2016; Howell et al., 2018; Dollinger \& Lodge, 2018; Herodotou et al., 2019). From a change management perspective, distributing power to individuals allows leadership to emerge and drive innovations that can address the needs of sub-groups in an organization and potentially be operationalized over a large scope (Uhl-Bien \& Arena, 2018). From the perspective of responsible and explainable AI, transparency is an important aspect that can be enhanced by promoting inclusive approaches such as giving users a level of control, an option to opt out, and an opportunity to participate in the design process (Hakami \& Hernández-Leo, 2020). However, the process of decision making in an LA cycle, from tool development or procurement and data collection to evaluations of impact and success, has been criticized for insufficient engagement with key users (Selwyn \& Gašević, 2020; Klein et al., 2019). Such exclusion can lead to distrust and low buy-in among individuals who feel that the adoption of LA is "forced upon" them (Klein et al., 2019).

An inclusive approach can enhance and leverage the autonomy of teachers to better align LA with pedagogical principles. As designers for learning (Goodyear, 2015), teachers are best placed to identify meaningful indicators of learning and determine whether the observed learning patterns match with pedagogical intents (Corrin, Kennedy, \& Mulder, 2013; Lodge \& Corrin, 2017; Baker et al., 2020). Excluding teachers from this process can lead to frustrations among teachers about LA misrepresenting or undermining pedagogical strategies and result in struggles to draw actionable insights from data (Brown, 2020). From the operational point of view, translating the values of LA to teachers is crucial for cultivating trust, especially when competing priorities leave little time and desire for exploring new technologies and teaching methods (Klein et al., 2019; Vigentini et al., 2020).

Although studies show that students generally have high trust that institutions will use their data responsibly (Slade et al., 2019; Jones et al., 2020; Tsai, Whitelock-Wainwright, \& Gašević, 2020), they have frequently expressed the desire to maintain control of their data and remain informed about how their data has been translated into action (Jones et al., 2019; Tsai, Perrotta, \& Gašević, 2019). An inclusive approach to LA acknowledges that the personal experience of learning places students in a knowledgeable position to judge the representation of learning in data (e.g., precision and completeness), fill in the missing gaps where data is not capturable (e.g., learning with alternative methods), and describe learning needs and struggles 
(Schumacher \& Ifenthaler, 2018; Baker et al., 2020). Scholars have also suggested that issues related to power imbalance, ethics, and privacy need to be addressed by involving students in LA processes (Herodotou et al., 2019; Jones et al., 2020). Nevertheless, recent studies continue to report imbalanced involvement of students in decision making related to LA (Tsai, Rates, et al., 2020; Buckingham Shum, Ferguson, \& Martinez-Maldonado, 2019).

A number of co-design models have been proposed to include multiple stakeholders in the development and implementation of LA. Chen and Zhu (2019) recommend a five-stage process to design a value-sensitive LA system: (1) identify relevant stakeholders' values, goals, and motivations through literature and empirical studies; (2) prototype tools based on the previous step; (3) work with relevant stakeholders to identify suitable ways to deploy the tools; (4) deploy the tools and gather user feedback; and (5) evaluate user experience, algorithmic accuracy, and impacts of LA. Similarly, Holstein, McLaren, and Aleven (2019) make four recommendations for co-designing LA systems: (1) start with the needs of stakeholders, (2) connect analytics to actions that teachers may take in real-world contexts, (3) prototype user tasks and usage scenarios, and (4) prototype the behaviour of LA tools based on a diversity of real-world data sets. Prieto-Alvarez, Martinez-Maldonado, and Anderson (2018) propose a model that includes four phases: understand, create, deliver, and support. In contrast to the approaches described above, Prieto-Alvarez et al. (2018) and Gray, Schalk, Rooney, and Lang (2021) highlight the support stage where both technical support and training (e.g., the development of data literacy) are required to help users understand, interpret, and act on data. Although co-design approaches can potentially address power imbalances and the relevant issues of ethics and privacy, it is worth noting that these approaches are not without challenges (Dollinger et al., 2019). For example, the lack of consensus or shared knowledge can take a significant amount of time for different stakeholders to understand the design context, identify a common language and design problems, and determine tools or approaches to address the problems (Thompson et al., 2018). In an attempt to bridge the communications gap between LA researchers, system developers, and teachers, Prieto, Rodríguez-Triana, Martínez-Maldonado, Dimitriadis, and Gašević (2019) have proposed the OrLA framework, which covers 23 different topics that are important to the adoption of LA at the classroom level.

In addition to co-design approaches, cultivating trust in LA needs committed leadership and sound policy. For example, Dawson and colleagues (2018) and Tsai, Poquet, and colleagues (2019) suggest that a complexity leadership model, comprising entrepreneurial leadership, operational leadership, and enabling leadership based on Uhl-Bien and Arena (2018), can effectively break down boundaries of internal networks in an institution, addressing challenges related to stakeholder buy-in, institutional culture, ethics, and privacy. In recent years, there have been significant efforts at promoting policy development to ensure responsible adoption of LA, e.g., The Open University's Policy on Ethical Use of Student Data for Learning Analytics (The Open University, 2014), Jisc's Code of Practice (Sclater \& Bailey, 2015), and the SHEILA framework (Tsai et al., 2018). Among these, the SHEILA framework highlights direct engagement with different stakeholders to identify key actions and challenges related to LA goal-setting, change management and strategy, and evaluations of impact. An application of this framework at two Australian universities has allowed socio-technical issues that hamper the sustainability and scalability of LA to be identified (Vigentini et al., 2020).

The adoption of LA in complex educational systems is woven into sociocultural and technical challenges that together contribute to several trust issues worthy of careful inspection to ensure their alignment with educational and human values. To this end, the next section outlines the rationale of our study design, which aimed to present views from both teachers and students about aspects of LA that are trustworthy or not in their institutional context.

\section{Methodology}

This work is based on an exploratory study that adopted both survey and focus group methods to investigate issues that hamper trust in LA from the perspectives of teaching staff and students. The study was approved by the ethics committee of the Moray House School of Education at the University of Edinburgh. Participants were based at a large UK university with more than 40,000 students. The research activities took place in 2017 along with other activities that served to identify strategic directions for LA and inform the policy procedure. The university was at the early stage of exploring LA, and the majority of teaching staff and students did not have experience with LA. Thus, both the survey and the focus group activities started with a brief introduction to $\mathrm{LA}^{1}$. We describe the research design below.

\subsection{Survey and Focus Group Design}

The teaching staff survey has 22 items (Appendix 7.1), and the student survey has 12 items (Appendix 7.2), also known as SELAQ (see Whitelock-Wainwright, Gašević, Tejeiro, Tsai, and Bennett (2019) for details of the validation process). Both questionnaires were designed to measure expectations of LA services by comparing ideal expectations (what users desire)

\footnotetext{
${ }^{1}$ The full introductory text used for each research activity can be accessed by downloading the research instruments from https: / sheilaproject .eu/sheila-framework/.
} 
and predicted expectations (what users expect to see in reality). Both the ratings of predicted expectations and the gap between predicted and ideal expectations may indicate levels of trust. The lower the predicted expectation, the less respondent confidence is observed in seeing a statement being realized in the institution. Similarly, the larger the gap between ideal and predicted expectations (with the latter being lower), the greater distance is observed between a desired state and the confidence in seeing it being realized in reality. Responses to each of the survey items are made on two seven-point Likert scales ( 1 = Strongly Disagree, 7 = Strongly Agree) that reflect two levels of expectations: ideal ("Ideally, I would like this to happen") and predicted ("In reality, I expect this to happen"). All participants needed to give their consent before starting the survey, and an option to opt in to a prize draw was offered as an incentive. The full questionnaires are accessible at https://bit.ly/staff_student_questionnaires.

The focus groups were facilitated with 10 semi-structured questions focusing on exploring experience with existing data practices at the university and expectations about addressing learning and teaching challenges using LA (Appendices 7.3 and 7.4). All participants signed a consent form to participate in the study and agreed to have their conversations recorded. Each focus group lasted for an hour. Refreshments were provided to each staff participant, and $£ 10$ was offered to each student participant in gratitude for their time.

\subsection{Participants}

A total of 674 responses to the student questionnaire were collected (female $=429,63.65 \% ; 10.11 \%$ response rate). Respondents were aged between 18 and 72, with a mean age of $24.50(\mathrm{SD}=7.94)$. The majority of the sample were undergraduate students $(n=396,58.80 \%)$, followed by PhD students $(n=216,32 \%)$, and then master's students $(n=62,9.20 \%)$. A total of $31.20 \%$ $(n=210)$ of students were studying a subject from the arts and humanities, $24 \%(n=162)$ were taking a subject within the faculty of science, $19.30 \%(n=130)$ stated they were taking a social science subject, $15.30 \%(n=103)$ of students were from the faculty of medicine and health sciences, and $10.20 \%(n=69)$ were from engineering departments. The sample comprised 475 domestic students $(70.50 \%)$ and 199 international students $(29.50 \%)$.

A total of 81 responses to the staff questionnaire were collected. The gender breakdown is as follows: 41 were male (50.61\%), 39 were female $(48.15 \%)$, and one preferred not to say $(1.24 \%)$. Nineteen $(23.46 \%)$ of the teaching staff sample were from the faculty of science, one (1.24\%) member of staff was from the faculty of engineering, $36(44.44 \%)$ members of staff were from the faculty of social science, $19(23.46 \%)$ were from the faculty of arts and humanities, and six $(7.41 \%)$ were from the faculty of medicine and veterinary medicine. Job roles of the sample were as follows: 24 (29.63\%) members of staff were lecturers, $18(22.22 \%)$ were senior lecturers, three (3.70\%) were readers, $21(25.93 \%)$ were professors, five $(6.17 \%)$ were teaching fellows, seven (8.64\%) were senior teaching fellows, two (8.64\%) responded with other, and one (1.24\%) reported that their role encompassed three roles (lecturer, senior lecturer, and other). Administrative roles for the sample of teaching staff were as follows: two (2.47\%) were heads of schools, one (1.24\%) was a dean, 17 (20.99\%) were program directors, 33 (40.74\%) responded with other, $24(40.74 \%)$ stated not applicable, and four (4.94\%) stated that their role was both a program director and other.

The focus group participants were sampled from all of the colleges in the university, and the selection process focused on diversifying disciplines. A total of 26 students ( 7 males, 19 females) and 18 teaching staff ( 10 males, 8 females) participated in the focus groups. The student participants were divided into six groups: four undergraduate groups, one postgraduate group, and one online distance learning group. The staff participants were divided into five groups. Five of the participants had director roles (e.g., program director or director of undergraduate studies) and three had personal tutor ${ }^{2}$ roles.

\subsection{Data Analysis}

\subsubsection{Survey: Statistical Analysis}

Descriptive statistics, in the form of frequencies and percentages, were used to undertake an exploratory analysis of the questionnaire responses. Paired t-tests were used to compare responses across the two expectation categories (ideal and predicted) (see Appendices 7.5.1 and 7.5.2 for test results).

\subsubsection{Focus Groups: Thematic Analysis}

The focus group interviews were transcribed and then analyzed using a thematic coding method (Grbich, 2012). The coding schemes were developed inductively, which involved one researcher reading the transcripts repetitively to identify recurring themes and types of issues raised. The qualitative analysis tool Nvivo was employed to assist in this process. In total, 64 codes categorized into three main themes and 14 sub-themes were developed to analyze student focus groups (accessible at http://bit.ly/students_coding), while 59 codes categorized into three main themes and 26 sub-themes were

\footnotetext{
${ }^{2}$ A personal tutor in the UK higher-education sector is a member of academic staff who provides academic guidance and pastoral support to a student during their course of study.
} 
developed to analyze staff focus groups (accessible at http://bit. Iy/staff_coding). Subsequently, four researchers worked together to check the coding scheme for validity. The same researcher who developed the coding scheme then carried out the analysis.

In the following sections, quotes from the staff focus groups are labelled with TG (teacher group), and those from the student focus groups are labelled with SG (student group), with numbers to differentiate different groups. The participants are denoted as R (respondent) followed by a number to differentiate participants in the same group. For example, TG1-R1 indicates Respondent 1 from Staff Focus Group 1, and SG2-R2 indicates Respondent 2 from Student Focus Group 2. Participants in SG1 to SG4 are undergraduate students, SG5 are postgraduate students, and SG6 are online distance learning students (usually mature, part-time students). The selected excerpts are faithful to the original responses, with the minor exception that some redundant words, such as "like," were edited out whenever they were not considered to contribute significant meaning to the study. In many cases when quotes were extracted from the transcripts, it was necessary to select relevant information to present. In these cases, we used [...] to indicate omissions.

\section{Findings}

In this section, we answer the two research questions. Section 4.1 presents results of the staff and student surveys according to RQ1— "In what areas do students and teachers trust or distrust the university to implement LA?" Section 4.2 presents results of focus groups with staff and students in response to RQ2- "What are the threats to trustworthy implementation of LA?"

\subsection{Areas of (Dis)trust}

Tables 1 and 2 show the results of staff and student surveys, respectively. Each table summarizes the average rating of each item in terms of ideal and predicted expectations in addition to the difference between the two expectations. Figures 1 and 2 visualize the ideal and predicted expectations based on means (see Tables 1 and 2).

Table 1. Summary of staff expectations, sorted by the mean difference (ideal minus predicted expectations) tables/mean ${ }_{s}$ aff $f_{1} . c s v$

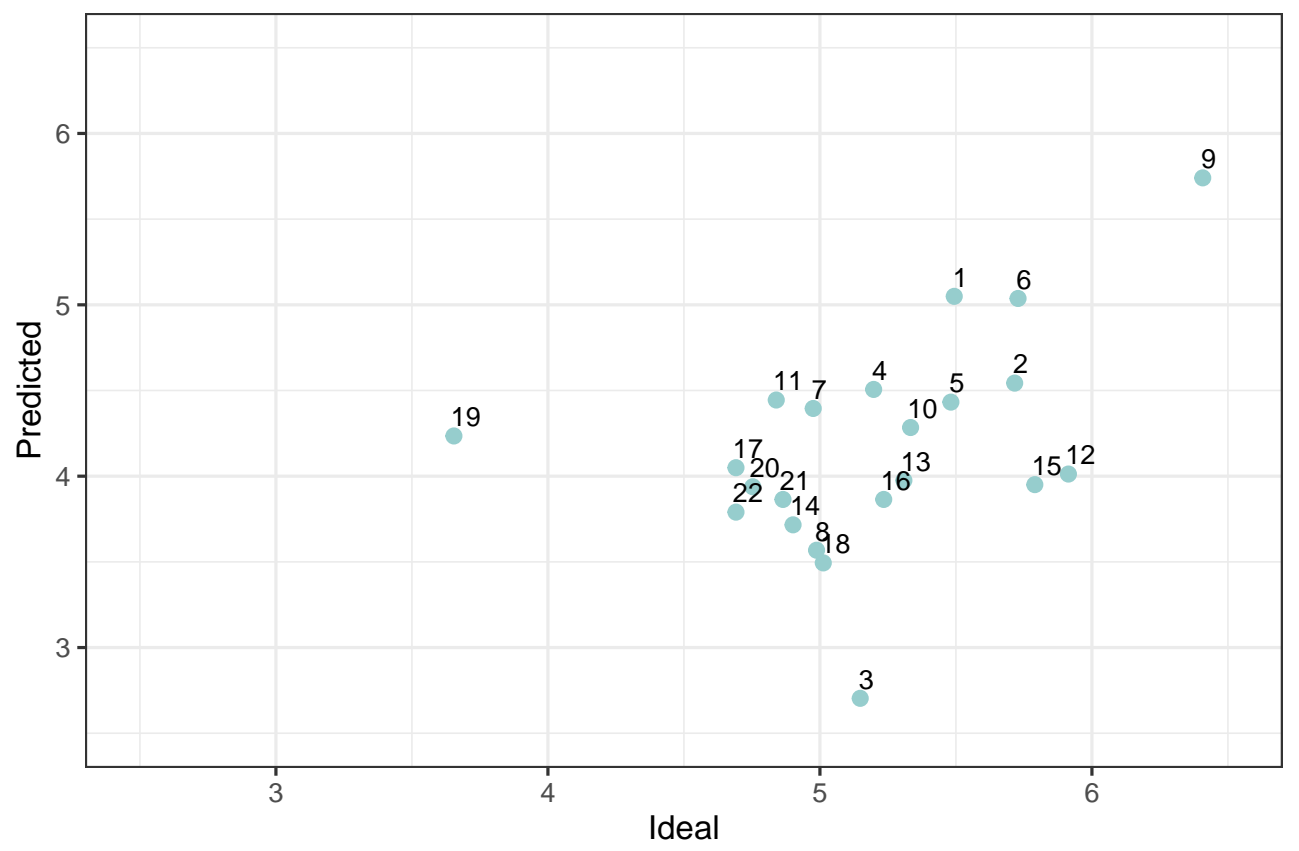

Figure 1. Ideal and predicted expectations based on means (staff survey), labelled by question numbers (see Table 1).

In terms of staff expectations, the mean difference between ideal and predicted expectations ranges between -0.58 and 2.44, as shown in Table 1 (see Appendix 7.1 for a full description of survey items). A paired t-test shows a significant difference between ideal and predicted expectations across all items except for Items 1, 11, and 19 (Appendix 7.5.1), indicating areas of the least difference between what the respondents desired and what they expected to see in reality. Items with small gaps 
between ideal and predicted expectations usually indicate areas that require the least attention or efforts to improve on when it comes to expectation management. For example, Item 11 (Update students about their learning progress) has the lowest absolute difference between ideal and predicted expectations, which indicates relatively high trust among respondents in this aspect. However, the same interpretation does not apply to Item 19 (Staff will have an obligation to act on LA) since the difference between its average ideal expectation rating and predicted expectation is negative, and the ideal expectation rating is the lowest among all items. This indicates that the respondents found this aspect the least desirable and yet the belief of seeing it happen in reality is higher than desired. On the other hand, Item 3 (LA will not increase my workload) received the lowest average rating of predicted expectation and had the largest gap of ratings between predicted and ideal expectations. A paired t-test shows a significant difference between the two expectations with a large effect size (Cohen, 1992) $(p=2.99 e-10$, $d=1.21$; see Appendix 7.5.1). This indicates an aspect of the highest distrust among the respondents. Both Item 3 and Item 19 reveal areas most likely to cause dissatisfaction among the teaching staff. Figure 1 shows that the respondents had the highest ideal and predicted expectations of the university to have an ethics and privacy protection policy in place (Item 9). This indicates an area that is perceived as particularly important to the respondents, and the confidence in seeing it happen in reality is relatively high. By contrast, Item 12 (LA will collect and present data that is accurate) and Item 15 (LA feedback will be understandable and easy to read), although receiving the second- and third-highest ratings of ideal expectations, respectively, have the second- and third-largest gaps from predicted expectations (see Table 1). T-test results show a significant difference between ideal and predicted expectations, with a large effect size (Cohen, 1992) for both items (Item 12: $p=2.72 e-14$, $d=1.26$; Item 15: $p=5.33 e-15, d=1.20$; see Appendix 7.5.1). This indicates that both areas are highly likely to attract dissatisfaction and distrust.

Table 2. Summary of student expectations, sorted by the mean difference (ideal minus predicted expectations) tables/mean tudent $_{1} . c s v$

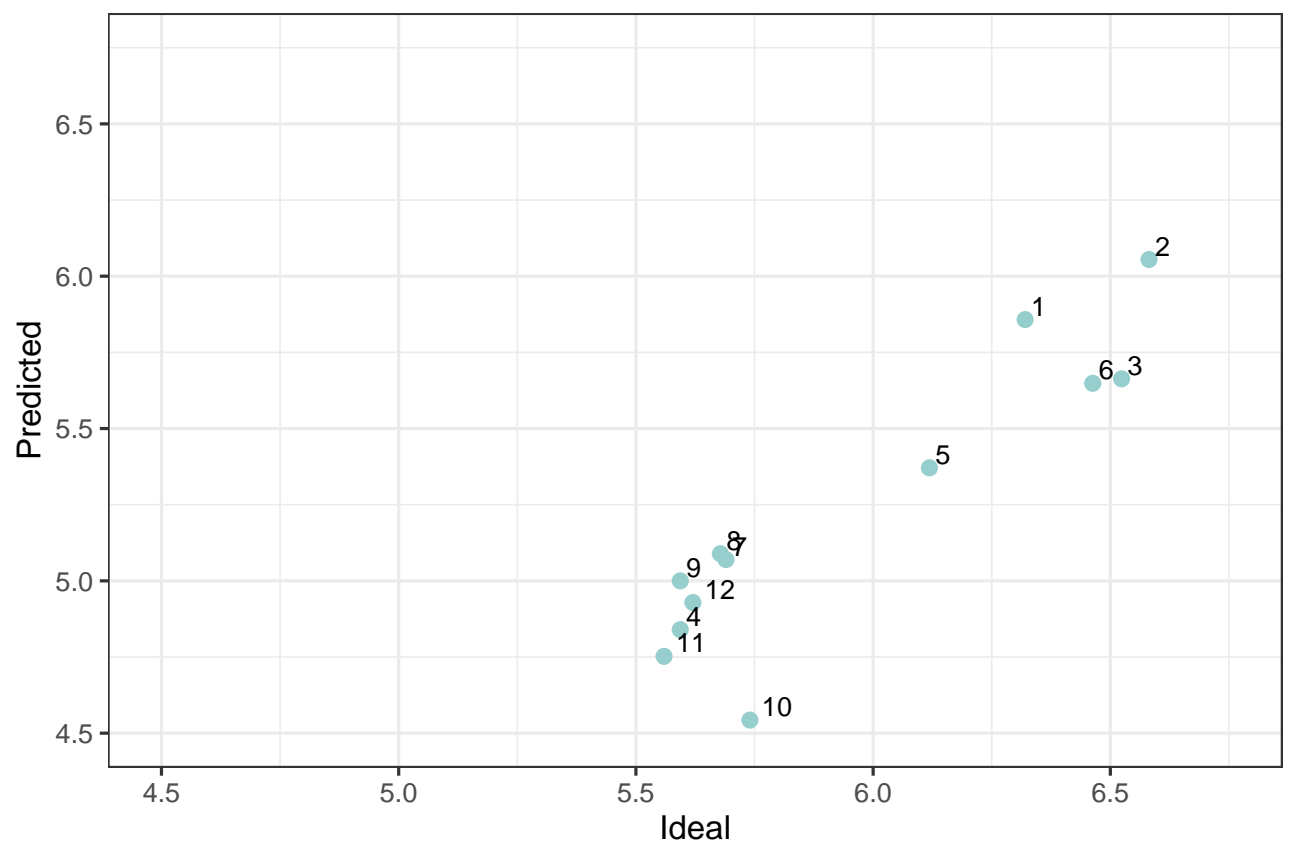

Figure 2. Ideal and predicted expectations based on means (student survey), labelled by question numbers (see Table 2).

In terms of student expectations, the mean difference between ideal and predicted expectations ranges between 0.46 and 1.20, as shown in Table 2 (see Appendix 7.2 for a full description of survey items). A paired t-test shows significant differences between ideal and predicted expectations across all items (Appendix 7.5.2). Item 10 (Staff will be competent in incorporating LA) received the lowest average rating of predicted expectation and had the largest difference between predicted and ideal expectation ( $p=3.98 e-56, d=0.77$; see Appendix 7.5.2). This shows that the respondents had the least confidence and trust in the teaching staff's ability to incorporate LA into teaching and student support. In contrast, Item 1 (Seek consent before using identifiable data) received the second-highest average rating of predicted expectation and had the least difference between 
predicted and ideal expectations. This shows that the respondents were relatively confident about seeing this aspect realized in reality and that the urgency of improving this area may be lower when it comes to expectation management. Nevertheless, because the t-test results indicate a significant difference between ideal and predicted expectations across all 12 items, the institution should not ignore this area and the need to improve it further in order to maintain trust and improve satisfaction among students. Figure 2 shows that the respondents had the highest ideal and predicted expectations of the university to ensure the security of student data (Item 2), and the difference between the two expectations is the second lowest (see Table 2). This indicates an area that is the most important to the students, as well as showing that there is relatively high trust in the university to ensure it. By contrast, Item 3 (Seek consent if educational data is outsourced), although it received the second-highest average rating of ideal expectation, had the second-largest gap between ideal and predicted expectations (see Table 2) $(p=2.51 e-39$, $d=0.62$; see Appendix 7.5.2). This shows a sense of distrust in the university to seek student consent before outsourcing their data to external parties, and this aspect is likely to attract dissatisfaction or a sense of powerlessness.

\subsection{Threats to Trustworthy LA}

Our conversations with staff and students revealed a strong interest in using LA to enhance feedback (e.g., identifying strengths, weaknesses, and progress of learning) and tailored support for students in addition to informing curriculum planning and teaching delivery based on learning engagement and performance. However, various concerns expressed by the participants regarding the use of data for LA have surfaced issues that might impede the development of trust relationships and ownership of LA among key stakeholders. These threats are broadly related to unbalanced power relationships, ethical challenges, and inadequate human inputs.

\subsubsection{Threat 1: Caught in the Middle-Unbalanced Power Relationships}

Several participants in the staff focus groups expressed stress and frustration at striving to meet expectations from both managers and students while constantly feeling over-stretched in terms of time capacity (as also reflected in the staff survey; see Table 1) and sometimes undervalued about their professional judgment. For example, participants in TG4 pointed out the conflicts between the university's commitment to offering quality education and the limited capacity of staff to deliver promises:

R3: The university has actually done a bunch of things that basically end up raising student expectations about what we are going to be able to do and intervene and improve because of things that the university tells the students. And we can't always deliver on those. And I think this [LA] is another case where you have to be really careful because if you start collecting all of this data, the students may have an expectation that everyone is looking very closely at the data.

R1: Absolutely yeah.

R5: Yeah.

R3: And if they're in trouble someone's gonna come and tell them. And if we don't [...]

R3 \& R4: They could blame us. - TG4

The difficulty of managing expectations from managers and students coupled with the common issue of time pressure among teaching staff has placed a barrier in the way of the uptake of LA despite its potential to increase understanding of student learning. Instead of seeing LA as a way to ease the challenges of managing large cohorts, several participants perceived LA as potentially an extra load of data to "wade through" and additional demands on time and effort.

There was a sense of distrust in institutional implementation of LA, partly due to the lack of consensus on staff capacity and partly due to the potential diminishment of professional autonomy. In particular, the latter relates to the power of decision making in the context of both teaching design and staff performance. Several participants related their experience of existing course evaluation frameworks and warned about the danger of data being interpreted without professional knowledge of learning and teaching design. For example, TG1-R1 raised concerns about LA being used against staff and TG3-R4 pointed out the risk of hampering teaching innovations as a result of performance judgment:

They get things like, "Oh the average student performance in your class last year was 4.3 out of 5 . This year it's 4.1 out of 5; how are you going to fix that?" It's like well that's meaningless. That's a natural fluctuation that you expect to see. But these things are being applied very bluntly and very crudely by people who don't understand the nuance, who don't understand the context. - TG1-RI

I think it [LA] can lead to worse teaching, because everybody's gonna be regressing towards a kind of safe space. The danger is if you step out of it [...], immediately sort of red flashing lights go off and you're called in and 
you're hauled over the coals. And, you know, staff react to incentives. They will not do things which they think might be good. - TG3-R4

In a similar vein, TG5-R1 commented on the conflicts between teaching professionalism and quality assurance metrics that potentially drive institutional adoption of LA. In particular, TG5-R1's view flags the need to frame LA as a support tool that focuses on formative feedback:

As academics we are being de-professionalized. Broadly speaking we are not trusted to exercise our own discretion. There are too many regulatory processes which are designed to, you know, ensure that nothing goes wrong. Stuff goes wrong and what you need are people who are prepared and able and supported to make good decisions when things go wrong. - TG5-R1

Related to the frustration of measurements that discount pedagogical intents and complexities of learning in each unique context, the participants have also voiced a desire to exert agency in making professional decisions regarding the use of technologies in teaching, i.e., deciding whether an LA tool can support students to reach the desired learning outcomes for a course. The staff refused the idea of LA being implemented as a default tool for teaching or on an opt-out basis, as neither allows agency to be fully exercised without succumbing to the unbalanced power relationship between staff and the university. This finding may also explain the results of the staff survey, which reveal distrust in areas such as the obligation to act on LA and the accuracy and usability of LA (Table 1).

From the perspective of students, sharing data with the university is essentially a trade-off between retaining control of their data and receiving better educational support. Although passive acceptance was observed among students regarding giving consent as part of the enrolment process, the students generally shared a sense of trust in the university to use data rightfully and responsibly. As such, most of the participants did not actively seek to understand how the university processed and used their data. In general, the students "assumed" policies were in place and that they would only seek them out if issues occurred.

On the contrary, the students expressed distrust toward external parties that offer services to the university through accessing and processing data about students, as also shown in the survey findings (see Table 2). A general concern shared by the students is commercial targeting based on their existing experience both within and outside the university context. However, there is also a fear of "losing control" when data travels outside of the university:

I think once you start allowing some, it's quite hard to sort of regulate it. —SG4-R3

They [service providers] sell the data to a certain agency and then the agency is the one that distributes [data to] the others. If the agency misuses the law you can't directly go to the university when it comes to the legal things. $-S G 3-R 2$

When it comes to sharing data with staff, the students generally agreed that instructors and personal tutors can provide better support to students if given data that can help them identify the needs of individual students, e.g., educational history and student background. However, the participants expressed concerns about the development of biases as a result of certain types of data being highlighted:

I think if the tutor comes in there with the perception, "Oh she's the one that's been really struggling the whole time," even though you do very well in that particular course, I think it would affect the tutor's perception of you. $-S G 1-R 3$

Anything that would prejudice an outcome of my studies, I think would be something that I'd want to think pretty seriously about. $-S G 6-R 1$

$[\ldots]$

If you put a particular label or staple on a person you've then moved them into the centre stage and that's when I think you have to give the student a chance to opt out. —SG6-R4

In line with staff's worry about LA being used for performance judgment, here, the students shared their concern about decisions being made unfairly about them. 


\subsubsection{Threat 2: Ethical Challenges-Impact on Learning and Student Well-Being}

Despite the interest in leveraging decision making with data-based evidence, both teachers and students raised concerns about ethical dilemmas and inadvertent consequences on learning and student well-being. These dilemmas are particularly related to three areas: equity of treatment, learner autonomy, and affective impact.

Equity of treatment Related to the issue of potential prejudices, both teaching staff and students raised issues with equity of treatment. That is, when resources are limited, targeting support at particular groups of students may disadvantage others who are excluded or overlooked:

I suppose there could be an argument for equity of treatment. You're taking a particular class of students and you're putting much more effort into them than the rest. We can sort of say that part of education is being given the freedom to fail on your own, as opposed to school, you sort of learn from that. $-T G 2-R 4$

We want to have equal access to all the services at the university. $-S G 2-R 3$

$[\ldots]$

As long as the data collected results in services that are made open, for example, these people have studied different courses in high school, I will use this data to sort of design initial support program to, let's say, a tutoring session given to all students to sort of bring them up to university standards. —SG2-R4

Although both views are related to equity of treatment, the teaching staff member (TG2-R4) was particularly concerned about taking away learning opportunities from risk groups as a result of a prevention approach to learning support. The students, on the other hand, were concerned about losing opportunities of support if resources are directed away from them.

Learner autonomy In line with TG2-R4's concern about the autonomy of learners, i.e., the freedom to make decisions independent of one's own learning, other participants shared concerns about spoon-feeding students with LA-based recommendations. For example, TG3-R4 drew on their observation of the way the university responded to student satisfaction scores as a result of national surveys:

Telling them what they have to know, telling them that if they haven't, giving them sort of tests and stuff [...] Instead of saying "Students, listen, we need a dialogue about this," it's been more prescriptive action. -TG3-R4

In parallel with the freedom of choice regarding learning approaches, TG3-R4 also pointed out the freedom to escape "data gaze" (Beer, 2018):

About data observing people [...] This [the university] is meant to be a safe space for educational purposes, and as soon as we start applying big data thinking and being able to identify students in this kind of "Oh, you're not performing well," we are driven by, as an institution, by metrics.

Similarly, the students raised concerns about potential surveillance through tracking student activities, including geographic locations, library records, and online behaviour. Moreover, there appeared to be low awareness of what data is being collected and how it is being used, which resulted in a sense of powerlessness among the students in terms of retaining control of their data:

That's the problem, not about us providing the data but just about the transparency with how it is actually used, because we don't really know. "We agree" but it's very vague that it may be used in the future for improvement of services, that's very vague, that doesn't really say much. —SG3-R4

I wouldn't know what my data was used for, so then I wouldn't think, “Oh, maybe I should say I don't want my data to be used." - $-S G 3-R 3$

Although the students appeared to have limited awareness and freedom to fully exercise agency over the use of their data, some incidents shared by the teaching staff evidence the resistance of students to hegemonic control as a form of exerting agency: 
We put in a system where we give them [students] swipe cards and they swiped in to the lecture [...] And he [the lecturer] heard beep, beep, beep, beep, beep, beep and nobody came in [...] As soon as they realized they were being monitored, the students started subverting to it. $-T G 1-R 2$

$[\ldots]$

Many of our students are extremely resistant to being seen to be wrong about anything. They don't like making mistakes. They don't like being seen to make mistakes. - TG1-RI

The examples above show that under "data gaze" (Beer, 2018), learner agency may be exercised in a rebellious way that subverts educational intentions in order to serve personal interests, such as creating a perfect learner profile or avoiding punitive consequences.

Affective impact Although both staff and students welcomed data-based information that can increase the understanding of learning progress and needs, they perceived associated risks of impact on the psychological states of learners as a result of data being collected or the way information is communicated and interpreted. At the affective level, metrics-based performance and engagement inevitably foster competitions that, to some students, are motivating, but to others, can produce profound anxiety or discouragement.

The idea that you are being compared to everyone else in general is going to make you more anxious. $-T G 4-R 3$

When you see all those people actually learn much less and they perform at the same level, "What's wrong with me," that's what you could think basically. $-S G 3-R 4$

In addition, personalized recommendations may induce a sense of inadequacy or weakness, whereas treating students equally regardless of their backgrounds can risk student well-being and counter principles of equity:

Say you have a depression and then you get an email like, "Oh my god, you have a depression, we can help you with this, and this and that," that could make it worse sometimes than better if you keep having emails acknowledging it. -SG1-R3

From a helpful supportive point of view, there's a dichotomy between having anonymity and having general information [...] In some ways they [students] are being profiled, but on the other hand if that means the difference between them being successful and falling through the cracks $[\ldots]-T G 2-R 1$

The key questions raised regarding affective impact on students are twofold: (a) how to communicate information of support without demotivating students or inducing further anxiety, and (b) how to communicate positive information without leading to complacency and hence demotivation.

\subsubsection{Threat 3: Potential Misuse of LA-Inadequate Human Inputs}

The third threat to trustworthy LA is ineffective or undesirable uses of LA that undermine educational values. Key concerns are related to perceptions, presentations, and interpretations of learning that may vary significantly by individuals and contexts. The participants raised a number of questions, including the following: What does learning mean and look like? Is engagement equal to learning? How can learning in different contexts be captured and interpreted? Importantly, who is involved in this process?

Both the teaching staff and the students questioned the extent to which learning can be quantified. They cautioned against the notion of equating observable behaviour with learning:

R1: What you can see is what students do.

R2: Performance.

R1: Performance. What they come to, what they do in assessments, what they attend, what they hand in, what they look at online. But what you can't really tell and even our assessment is not great at this $[\ldots]$ is their learning. That's something that happens in the brain, in their mind. - TG1

With geophysics we went out to do a seismic survey, we interacted with the lecturer for three hours, we worked together to set up the equipment, but it's really hard to actually quantify what we learnt from it. Then I usually have five to six hours of labs every week on average, again most of it is I look at microscopic pin sections, I look at hand specimens, do cross sections, it's really hard to actually try to quantify it in numbers into a document for what I learned and how I learnt it. - SG3-R2 
The examples above also highlight the importance of aligning LA, from data collection to interpretation, with teaching designs that can be particular to individual courses and disciplines (Bakharia et al., 2016). A level of skepticism was observed among the teaching staff regarding the usefulness of feedback based on LA. On the one hand, learning can be a highly internalized process that is difficult to capture. On the other hand, inferring learning based on behavioural trends can risk generalization and sometimes merely renders redundant information if these trends are already predictable to instructors based on course designs, e.g., peaked activities closer to exam time:

It [LA] isn't actually useful to me because it doesn't particularly tell me that one of these things that I'm doing is more useful to them than anything else. And for the ones who are not engaging, it doesn't tell me why and how I can change that. $-T G 3-R 1$

It appears that LA can be useful by alluding to "what" is happening in learning spaces, but less informative in answering questions about "how" and "why" certain behaviours occur. As a result, both the teaching staff and the students emphasize the importance of "conversation" to fill in the gaps of an incomplete picture about learners:

It's sort of not reducing a person just to the figures that are being shown on your laptop regarding the person's performance [...] Interaction is the key. To understand the data you need to understand where it's coming from. $-S G 2-R 4$

It shouldn't be the tutor going, "I'm making this decision about you." It should be, "we both have this information, do you want to discuss it further?" - TG5-R2

Overall, there was a sense of distrust in areas such as disconnections between LA and learning design, downplaying the importance of social interactions between teachers and students, and discounting their inputs of unique knowledge about teaching and learning.

\section{Discussion}

The surveys and focus groups with teaching staff and students reveal areas that the university should work on to maintain or cultivate trust. The staff survey indicates high trust among the respondents in receiving guidance on accessing LA about students and having access to data about students in a degree program (Items 1 and 7, Table 1). There was also a strong belief that LA would be used to update students about their progress, and that the university should and would have an ethics and privacy protection policy in place (Items 11 and 9, Table 1). The last aspect particularly requires delicate care to maintain trust due to the high level of ideal expectation (Figure 1). On the other hand, the student survey indicates high trust in the university to keep their data safe and seek their consent before identifiable data is used (Table 2). Both aspects require careful governance at the policy level to maintain a trust relationship with students.

In terms of areas to cultivate trust, the surveys and focus groups identified issues that align with the literature (Numbers are subjective and Fear of power diminution; see Section 2.1) in addition to issues related to design and implementation of LA (Table 3).

Table 3. Areas to cultivate trust. Issues are highlighted in survey $(\mathrm{S})$, focus groups $(\mathrm{F})$, or both datasets (SF). Italicized text indicates shared concerns among teaching staff and students.

\begin{tabular}{llll}
\hline & \multicolumn{3}{c}{ Trust Issues } \\
\cline { 2 - 4 } & Numbers Are Subjective & Fear of Power Diminution & Design and Implementation \\
\hline \multirow{2}{*}{ Staff } & Data accuracy (S) & Professional autonomy (SF) & Workload (SF) \\
& Incomplete picture $(\mathrm{F})$ & Learner agency (F) & Interpretability \& ease of use (S) \\
& & & Actionable insights (F) \\
& & & Demotivating students $(\mathrm{F})$ \\
\hline \multirow{2}{*}{ Students } & Bias perpetuation $(\mathrm{F})$ & Staff competency (S) & Equal access to support (F) \\
& Incomplete picture $(\mathrm{F})$ & Transparency and control (SF) & Demotivating students $(\mathrm{F})$ \\
\hline
\end{tabular}


Numbers are subjective This issue confronts the misconception that data are neutral and numbers are objective. The staff survey reveals that the respondents generally distrusted LA to collect and present accurate data (Item 12, Table 1). This aspect may be related to the concerns expressed by focus group participants about the difficulty of capturing or quantifying learning. As already highlighted in the literature (Brown, 2020; Williamson et al., 2020), concerns about LA promoting a performative culture and a reductionist approach to understanding learning were observed among the staff; i.e., LA promotes or discourages certain behaviours while failing to adequately account for learning processes that are not easy to observe or are described by metrics. Similar concerns were shared by participants of student focus groups. However, the students also highlighted concerns about bias perpetuation (students being labelled by data) and fear of unfair assessment due to the bias. In line with the argument that LA dashboards can impose particular limits on how educators "see" students (Brown, 2020), the concerns raised here go beyond the issue of reductionism, underlining the potential difficulty for teaching staff to "unsee" certain data about students and make objective decisions about their current performance. In other words, so-called evidence-based decision making can be driven primarily by algorithms, which not only risks perpetuating or producing biases but also exonerates users from their own human biases if the concept of numbers being objective goes unchallenged.

Fear of power diminution This issue centres on the power flow in social processes that LA facilitates or embodies. From the teaching staff's point of view, both surveys and focus groups show a prevalent distrust that is rooted in the perception of LA as a form of control-conforming learning and teaching strategies. In terms of professional autonomy, the survey shows that staff were generally negative about the obligation to act on LA results and yet held a positive belief that this obligation would be imposed on them in reality (Item 19, Table 1). This issue is elaborated on by focus group participants as disrespect of their professional judgment on the best approaches to helping students develop academic and professional competencies in particular subjects. A related area of distrust is LA being used for performance judgment, as already highlighted in the literature (Kwet \& Prinsloo, 2020). On the other hand, the teaching staff expressed distrust in LA to empower learners in decision making. Various focus group participants shared concerns that LA would promote a spoon-feeding style of teaching, limiting opportunities for learners to exercise agency. By contrast, the student survey reveals distrust in staff's competency in incorporating LA into teaching and student support (Item 10, Table 2). In addition to potential problems of varying data literacy among staff, the concern raised here may be related to the bias issue discussed above, i.e., a concern that teaching staff would not be able to make a fair judgment based on LA and take appropriate actions toward teaching or student support. It is clear that both students and teaching staff were concerned about decisions made about them based on LA due to the power structures in the institution. That is, staff distrust managers who may use LA as a performance appraisal tool, and students distrust teaching staff who may use LA as an assessment tool.

As noted by Kwet and Prinsloo (2020), there is an increasing data flow between different stakeholders in an institution and with external service providers. Activities associated with such data flow have become arenas where power is negotiated and redistributed. As such, the students drew attention to issues around transparency and data control. Both the survey (Item 3, Table 2) and focus groups highlighted distrust in external parties due to the difficulty of tracking and deciding how data will be used. Although studies have shown that students generally trust the university to use their data responsibly (Slade et al., 2019; Jones et al., 2020), the focus group participants expressed a desire to have more information that can help them make decisions regarding sharing their data. Nevertheless, it is noted that student trust in the university can lead to disengagement with relevant policy documents about the use of their data, thus exacerbating the problem of information asymmetry and diminishing student control of their data (Tsai, Whitelock-Wainwright, \& Gašević, 2020). The amount of information per se is perhaps not the main problem here, but rather it is ineffective communication between the university and students.

Design and implementation In addition to the two areas of distrust highlighted in the literature, as discussed above, the study identified a number of trust issues related to how LA is designed and implemented. As far as the teaching staff were concerned, the constant struggle to balance workload and hence frustration about failing expectations have been a major barrier to developing trust in the institution's adoption of LA, as shown in both the survey (Item 3, Table 1) and focus groups. In addition, teaching staff also showed little confidence in LA being easy to interpret or use (Item 15, Table 1) and low trust in LA to provide useful information that alludes to reasons that certain behavioural patterns are present and how to act on them. It appears that the two common factors of technology acceptance (perceptions of usefulness and ease of use, see Davis, Bagozzi, and Warshaw (1989)) coupled with unbalanced workload have raised much doubt about the actual benefits of LA to teaching.

The teaching staff also expressed shared concerns with students regarding the potential of demotivating students with LA. We observed uncertainty among both staff and students in terms of effective ways to communicate LA-based feedback and recommendations to individuals. A related issue to personalized recommendations enabled by LA is the psychological burden on students who have been profiled and sorted into groups perceived as in need of special support, which may also limit the availability of resources to those not considered in need of support. Overall, distrust observed here suggests that LA deployment 
requires orchestration of both the system design and process management, particularly communication and distribution of both material and human resources.

\section{Reflections}

The findings of this study have highlighted the importance of maintaining existing trust with policy procedures and the need to cultivate trust by engaging with tensions rising from the social process of LA, particularly where the meaning of data and its associated power are negotiated between humans and algorithms, between humans and humans, and between individuals and the structural environment. Scholars have campaigned for inclusive approaches to sustainable LA, including co-designing technological solutions with key stakeholders (Prieto-Alvarez et al., 2018; Chen \& Zhu, 2019; Holstein et al., 2019; Dollinger \& Lodge, 2018); creating adaptive space through adopting a complexity leadership model (Dawson et al., 2018; Tsai, Poquet, et al., 2019); and situating policy development according to the needs, interests, and capacity of an institution and the members therein (Tsai et al., 2018). These approaches highlight an important step in understanding and incorporating the values and interests of relevant stakeholders. However, research has also shown challenges including time and effort required to reach consensus, lack of information or knowledge about domains outside one's own practice, and lack of confidence to drive change (Dollinger \& Lodge, 2018; Thompson et al., 2018). Our study serves to enhance the "understand" phase of a co-design process (Prieto-Alvarez et al., 2018) by highlighting important issues of trust to address when creating LA solutions or deployment strategies and relevant policy guidelines. Based on the findings, we highlight three points important to researchers, developers, decision-makers, and practitioners who share our interest in supporting learning with trustworthy LA.

1. LA is about human decisions As much as any data processing, LA relies on sorting and matching patterns based on data about learners that is obtainable in a learning environment (Selwyn, 2015). Indeed, this social practice is full of human decisions that need to be carefully inspected, justified, and even challenged to serve the purpose of enhancing learning, which includes caring for the well-being of students, allowing teaching staff to exercise professional judgment, and assisting institutions to identify needs for support. It is important to ask questions about numbers-where they come from, how they are (ir)relevant to individual students and courses, and why they present a particular picture about a student. These questions should inform decisions of technological developers when designing tools, of institutional managers when procuring and deploying LA, and of teaching staff and students when reflecting on an action to take. The fact that numbers carry human decisions is not a problem per se, but making a downstream decision based on numbers without critically interrogating their origins and implications can be as destructive as design decisions that fail to account for the complexity of learning and social factors.

2. LA is about reflections and actions Following on the previous point, LA is also about reflecting on factors that contribute to observed patterns and prompting actions as a result. The development of an LA system should consider feedback principles (Matcha, Uzir, Gašević, \& Pardo, 2020): feeding back, feeding up, and feeding forward (Hattie \& Timperley, 2007). In other words, LA needs to enable reflections on key questions, including what numbers tell us about the learning decisions and actions that students take, how the decisions and actions help students work toward desired goals or hamper them, and what strategies to take to bring about positive change. These feedback principles should also inform training for both teaching staff and students so as to cultivate appreciation and skills to make use of data-based feedback on both cognitive and affective levels.

3. LA is about the social process LA does not operate in a vacuum devoid of social context. On the contrary, institutional adoption is often driven by political interests (Ferguson, 2012; Tsai, Rates, et al., 2020), which do not necessarily align with the values held by teaching staff or students. While co-design approaches may help to develop a common vision and co-create values of LA (Dollinger et al., 2019), it is important to note the distribution of power and tensions as data flows from one party to another during the process of incorporating LA into a complex educational system. Operationalizing technological innovations requires adaptive leadership that engages with tensions, mobilizes resources, and cracks institutional silos to drive change (Uhl-Bien \& Arena, 2018). Therefore, the adoption of LA should not neglect the need to develop a community of learning and sharing where members of the institution can feel comfortable raising questions, exchanging experience, experimenting with thoughts, and clarifying goals and visions.

\section{Conclusion}

As voiced by experts in the field of LA, failing to consider social and political factors can prevent LA from making a positive contribution to education and society, and trusting people who develop and deploy LA is a key factor of users' feelings of unease toward LA (Ferguson et al., 2019). In this article, we have tried to unveil layers of complex socio-political issues that can impede trust in LA, highlighting issues related to perceptions of numbers, tensions deriving from unequal distribution of power in data processing and decision making in an LA cycle, and potential misalignment of LA with educational and human 
values. Our reflections on the observed phenomenon of trust call attention to the following areas when adopting LA: (1) key stakeholders of LA need to cultivate a critical awareness of the socio-political aspects of data so as to interrogate implications about decisions (or interpretations) that they themselves or others make about data; (2) LA needs to be designed to fulfill functions of feedback in learning, and end-users need to develop appreciation of data-based feedback and skills to translate feedback into action; and (3) institutional leadership should create opportunities for different stakeholders to express personal values and interests about LA (e.g., through co-design meetings) and address tensions that may derive from imbalanced power relationships (e.g., creating a code of practice).

\section{Acknowledgements}

We would like to thank the participants of this study for their generous contributions.

\section{Declaration of Conflicting Interest}

The authors declared no potential conflicts of interest with respect to the research, authorship, and/or publication of this article.

\section{Funding}

This work was supported by the Erasmus+ Programme of the European Union [562080-EPP-1-2015-1-BE-EPPKA3-PIFORWARD]. The European Commission support for the production of this publication does not constitute an endorsement of the contents, which reflect the views only of the authors, and the Commission will not be held responsible for any use that may be made of the information contained therein.

\section{References}

Arnold, K. E., Lonn, S., \& Pistilli, M. D. (2014). An exercise in institutional reflection: The learning analytics readiness instrument (LARI). In Proceedings of the Fourth International Conference on Learning Analytics and Knowledge (LAK 2014), 24-28 March 2014, Indianapolis, IN, USA (pp. 163-167). New York: ACM. https://doi.org/10.1145/ 2567574.2567621

Baker, R., Xu, D., Park, J., Yu, R., Li, Q., Cung, B., ... Smyth, P. (2020). The benefits and caveats of using clickstream data to understand student self-regulatory behaviors: Opening the black box of learning processes. International Journal of Educational Technology in Higher Education, 17, 1-24. https://doi.org/10.1186/s41239-020-00187-1

Bakharia, A., Corrin, L., De Barba, P., Kennedy, G., Gašević, D., Mulder, R., ... Lockyer, L. (2016). A conceptual framework linking learning design with learning analytics. In Proceedings of the Sixth International Conference on Learning Analytics and Knowledge (LAK 2016), 25-29 April 2016, Edinburgh, UK (pp. 329-338). New York: ACM. https://doi.org/10.1145/2883851.2883944

Beer, D. (2018). The Data Gaze: Capitalism, Power and Perception. Sage.

Brown, M. (2020). Seeing students at scale: How faculty in large lecture courses act upon learning analytics dashboard data. Teaching in Higher Education, 25(4), 384-400. https://doi.org/10.1080/13562517.2019.1698540

Buckingham Shum, S., Ferguson, R., \& Martinez-Maldonado, R. (2019). Human-centred learning analytics. Journal of Learning Analytics, 6(2), 1-9. https://doi.org/10.18608/jla.2019.62.1

Castañeda, L., \& Selwyn, N. (2018). More than tools? Making sense of the ongoing digitizations of higher education. International Journal of Educational Technology in Higher Education, 15, 22. https://doi.org/10.1186/s41239-018-0109 $-\mathrm{y}$

Chen, B., \& Zhu, H. (2019). Towards value-sensitive learning analytics design. In Proceedings of the Eighth International Conference on Learning Analytics and Knowledge (LAK 2019), 4-8 March 2019, Tempe, AZ, USA (pp. 343-352). New York: ACM. https://doi.org/10.1145/3303772.3303798

Cohen, J. (1992). A power primer. Psychological Bulletin, 112(1), 155. https://doi.org/10.1037/0033-2909.112.1.155

Corrin, L., Kennedy, G., \& Mulder, R. (2013). Enhancing learning analytics by understanding the needs of teachers. In Proceedings of the Australian Society for Computers in Learning in Tertiary Education 30th Annual Conference (ASCILITE 2013), 1-4 December 2013, Sydney, Australia (pp. 201-205). Retrieved from https: / / ascilite.org/ conferences/sydney13/program/papers/Corrin.pdf

Davis, F. D., Bagozzi, R. P., \& Warshaw, P. R. (1989). User acceptance of computer technology: A comparison of two theoretical models. Management science, 35(8), 982-1003. Retrieved from https: / /www. jstor.org/stable/2632151 
Dawson, S., Joksimovic, S., Poquet, O., \& Siemens, G. (2019). Increasing the impact of learning analytics. In Proceedings of the Eighth International Conference on Learning Analytics and Knowledge (LAK 2019), 4-8 March 2019, Tempe, AZ, USA (pp. 446-455). New York: ACM. https://doi.org/10.1145/3303772.3303784

Dawson, S., Poquet, O., Colvin, C., Rogers, T., Pardo, A., \& Gašević, D. (2018). Rethinking learning analytics adoption through complexity leadership theory. In Proceedings of the Eighth International Conference on Learning Analytics and Knowledge (LAK 2018), 5-9 March 2018, Sydney, Australia (pp. 236-244). New York: ACM. https://doi.org/10.1145/ 3170358.3170375

Dollinger, M., Liu, D., Arthars, N., \& Lodge, J. (2019). Working together in learning analytics towards the co-creation of value. Journal of Learning Analytics, 6(2), 10-26. https://doi.org/10.18608/jla.2019.62.2

Dollinger, M., \& Lodge, J. M. (2018). Co-creation strategies for learning analytics. In Proceedings of the Eighth International Conference on Learning Analytics and Knowledge (LAK 2018), 5-9 March 2018, Sydney, Australia (pp. 97-101). New York: ACM. https://doi.org/10.1145/3170358.3170372

Drachsler, H., \& Greller, W. (2016). Privacy and analytics: It's a DELICATE issue. a checklist for trusted learning analytics. In Proceedings of the Sixth International Conference on Learning Analytics and Knowledge (LAK 2016), 25-29 April 2016, Edinburgh, UK (pp. 89-98). New York: ACM. https://doi.org/10.1145/2883851.2883893

Ferguson, R. (2012). Learning analytics: Drivers, developments and challenges. International Journal of Technology Enhanced Learning, 4(5/6), 304-317. https://doi.org/10.1504/IJTEL.2012.051816

Ferguson, R., Clow, D., Griffiths, D., \& Brasher, A. (2019). Moving forward with learning analytics: Expert views. Journal of Learning Analytics, 6(3), 43-59. https://doi.org/10.18608/jla.2019.63.8

Ferguson, R., Hoel, T., Scheffel, M., \& Drachsler, H. (2016). Guest editorial: Ethics and privacy in learning analytics. Journal of Learning Analytics, 3(1), 5-15. https://doi.org/10.18608/jla.2016.31.2

Gašević, D., Dawson, S., \& Siemens, G. (2015). Let's not forget: Learning analytics are about learning. TechTrends, 59(1), 64-71. https://doi.org/10.1007/s11528-014-0822-X

Gašević, D., Kovanović, V., \& Joksimović, S. (2017). Piecing the learning analytics puzzle: A consolidated model of a field of research and practice. Learning: Research and Practice, 3(1), 63-78. https://doi.org/10.1080/23735082.2017.1286142

Gašević, D., Tsai, Y.-S., Dawson, S., \& Pardo, A. (2019). How do we start? An approach to learning analytics adoption in higher education. The International Journal of Information and Learning Technology, 36(4), 342-353. https://doi.org/ 10.1108/IJILT-02-2019-0024

Goodyear, P. (2015). Teaching as design. HERDSA Review of Higher Education, 2(2), 27-50.

Gray, G., Schalk, A., Rooney, P., \& Lang, C. (2021). A stakeholder informed professional development framework to support engagement with learning analytics. In Proceedings of the 11th International Conference on Learning Analytics and Knowledge (LAK 2021), 12-16 April 2021, online (pp. 237-247). New York: ACM. https://doi.org/10.1145/ 3448139.3448162

Grbich, C. (2012). Qualitative Data Analysis: An Introduction. Sage.

Hakami, E., \& Hernández-Leo, D. (2020). How are learning analytics considering the societal values of fairness, accountability, transparency and human well-being? A literature review. In LASI-SPAIN 2020: Learning Analytics Summer Institute (Spain 2020: Learning Analytics. Time for Adoption?), 15-16 June 2020, Valladolid, Spain (pp. 121-141). Aachen, Germany: CEUR. Retrieved from http: / / ceur-ws.org/Vol-2671/paper12.pdf

Hattie, J., \& Timperley, H. (2007). The power of feedback. Review of Educational Research, 77(1), 81-112. https://doi.org/ $10.3102 / 003465430298487$

Herodotou, C., Rienties, B., Boroowa, A., Zdrahal, Z., \& Hlosta, M. (2019). A large-scale implementation of predictive learning analytics in higher education: The teachers' role and perspective. Educational Technology Research and Development, 67(5), 1273-1306. https://doi.org/10.1007/s11423-019-09685-0

Holstein, K., McLaren, B. M., \& Aleven, V. (2019). Co-designing a real-time classroom orchestration tool to support teacher-AI complementarity. Journal of Learning Analytics, 6(2), 27-52. https://doi.org/10.18608/jla.2019.62.3

Howell, J. A., Roberts, L. D., Seaman, K., \& Gibson, D. C. (2018). Are we on our way to becoming a "helicopter university"? Academics' views on learning analytics. Technology, Knowledge and Learning, 23(1), 1-20. https://doi.org/10.1007/ s10758-017-9329-9

Ifenthaler, D., \& Schumacher, C. (2016). Student perceptions of privacy principles for learning analytics. Educational Technology Research and Development, 64(5), 923-938. https://doi.org/10.1007/s11423-016-9477-y

Jones, K. M., Asher, A., Goben, A., Perry, M. R., Salo, D., Briney, K. A., \& Robertshaw, M. B. (2020). "We're being tracked at all times": Student perspectives of their privacy in relation to learning analytics in higher education. Journal of the Association for Information Science and Technology. https://doi.org/10.1002/asi.24358 
Jones, K. M., Rubel, A., \& LeClere, E. (2019). A matter of trust: Higher education institutions as information fiduciaries in an age of educational data mining and learning analytics. Journal of the Association for Information Science and Technology, 71(10), 1227-1241. https://doi.org/10.1002/asi.24327

Jovanovic, J., Gasevic, D., Brooks, C., Devedzic, V., Hatala, M., Eap, T., \& Richards, G. (2007). Using semantic web technologies to analyze learning content. IEEE Internet Computing, 11(5), 45-53. https://doi.ieeecomputersociety.org/ 10.1109/MIC.2007.116

Klein, C., Lester, J., Rangwala, H., \& Johri, A. (2019). Learning analytics tools in higher education: Adoption at the intersection of institutional commitment and individual action. The Review of Higher Education, 42(2), 565-593. https://doi.org/10.1353/rhe.2019.0007

Knox, J. (2017). Data power in education: Exploring critical awareness with the "Learning Analytics Report Card". Television \& New Media, 18(8), 734-752. https://doi.org/10.1177/1527476417690029

Kwet, M., \& Prinsloo, P. (2020). The "smart" classroom: A new frontier in the age of the smart university. Teaching in Higher Education, 1-17. https://doi.org/10.1080/13562517.2020.1734922

Lang, C., Macfadyen, L. P., Slade, S., Prinsloo, P., \& Sclater, N. (2018). The complexities of developing a personal code of ethics for learning analytics practitioners: Implications for institutions and the field. In Proceedings of the Eighth International Conference on Learning Analytics and Knowledge (LAK 2018), 5-9 March 2018, Sydney, Australia (pp. 436-440). New York: ACM. https://doi.org/10.1145/3170358.3170396

Leitner, P., Khalil, M., \& Ebner, M. (2017). Learning analytics in higher education-A literature review. In A. Peña-Ayala (Ed.), Learning Analytics: Fundaments, Applications, and Trends (pp. 1-24). Springer. https://doi.org/10.1007/ 978-3-319-52977-6_1

Lodge, J. M., \& Corrin, L. (2017). What data and analytics can and do say about effective learning. npj Science of Learning, 2, 5. https://doi.org/10.1038/s41539-017-0006-5

Lodge, J. M., \& Lewis, M. J. (2012). Pigeon pecks and mouse clicks: Putting the learning back into learning analytics. In M. Brown, M. Hartnett, \& T. Stewart (Eds.), Proceedings of the 29th Annual Conference of the Australian Society for Computers in Learning in Tertiary Education (ASCILITE 2012), 25-28 November 2012, Wellington, New Zealand (pp. 560-564). Australian Society for Computers in Learning in Tertiary Education. Retrieved from https://www.ascilite.org/conferences/Wellington12/2012/images/custom/ lodge, _jason_-_pigeon_pecks.pdf

Long, P., Siemens, G., Conole, G., \& Gašević, D. (2011). Proceedings of the International Conference on Learning Analytics and Knowledge. In Proceedings of the First International Conference on Learning Analytics and Knowledge (LAK 2011), 27 February-1 March 2011, Banff, AB, Canada. New York: ACM.

Macfadyen, L. P., Dawson, S., Pardo, A., \& Gašević, D. (2014). Embracing big data in complex educational systems: The learning analytics imperative and the policy challenge. Research \& Practice in Assessment, 9(Winter), 17-28.

Matcha, W., Gašević, D., Uzir, N. A., Jovanović, J., \& Pardo, A. (2019). Analytics of learning strategies: Associations with academic performance and feedback. In Proceedings of the Eighth International Conference on Learning Analytics and Knowledge (LAK 2019), 4-8 March 2019, Tempe, AZ, USA (pp. 461-470). New York: ACM. https://doi.org/10.1145/ 3303772.3303787

Matcha, W., Uzir, N. A., Gašević, D., \& Pardo, A. (2020). A systematic review of empirical studies on learning analytics dashboards: A self-regulated learning perspective. IEEE Transactions on Learning Technologies, 13(2), 226-245. https://doi.org/10.1109/TLT.2019.2916802

Norris, C., \& Lyon, D. (2003). Surveillance as Social Sorting: Privacy, Risk, and Digital Discrimination. Routledge.

Oster, M., Lonn, S., Pistilli, M. D., \& Brown, M. G. (2016). The learning analytics readiness instrument. In Proceedings of the Sixth International Conference on Learning Analytics and Knowledge (LAK 2016), 25-29 April 2016, Edinburgh, UK (pp. 173-182). New York: ACM. https://doi.org/10.1145/2883851.2883925

Pardo, A., Jovanovic, J., Dawson, S., Gašević, D., \& Mirriahi, N. (2019). Using learning analytics to scale the provision of personalised feedback. British Journal of Educational Technology, 50(1), 128-138. https://doi.org/10.1111/bjet.12592

Pardo, A., \& Siemens, G. (2014). Ethical and privacy principles for learning analytics. British Journal of Educational Technology, 45(3), 438-450. https://doi.org/10.1111/bjet.12152

Prieto, L. P., Rodríguez-Triana, M. J., Martínez-Maldonado, R., Dimitriadis, Y., \& Gašević, D. (2019). Orchestrating learning analytics (OrLA): Supporting inter-stakeholder communication about adoption of learning analytics at the classroom level. Australasian Journal of Educational Technology, 35(4). https://doi.org/10.14742/ajet.4314 
Prieto-Alvarez, C. G., Martinez-Maldonado, R., \& Anderson, T. (2018). Co-designing learning analytics tools with learners. In J. M. Lodge, J. C. Horvath, \& L. Corrin (Eds.), Learning Analytics in the Classroom: Translating Learning Analytics Research for Teachers. Abingdon-on-Thames, UK: Routledge. https://doi.org/10.4324/9781351113038

Prinsloo, P., \& Slade, S. (2015). Student privacy self-management: Implications for learning analytics. In Proceedings of the Fifth International Conference on Learning Analytics and Knowledge (LAK 2015), 16-20 March 2015, Poughkeepsie, NY, USA (pp. 83-92). New York: ACM. https://doi.org/10.1145/2723576.2723585

Prinsloo, P., \& Slade, S. (2016). Student vulnerability, agency, and learning analytics: An exploration. Journal of Learning Analytics, 3(1), 159-182. https://doi.org/10.18608/jla.2016.31.10

Prinsloo, P., Slade, S., \& Khalil, M. (2018). Stuck in the middle? Making sense of the impact of micro, meso and macro institutional, structural and organisational factors on implementing learning analytics. In A. Volungeviciene \& A. Szúcs (Eds.), Proceedings of the 27th Annual Conference of the European Distance and E-learning Network (EDEN 2018), 17-20 June 2018, Genoa, Italy (pp. 326-334). European Distance and E-learning Network. Retrieved from http: //oro.open.ac.uk/55598/

Roberts, L. D., Howell, J. A., Seaman, K., \& Gibson, D. C. (2016). Student attitudes toward learning analytics in higher education: "The fitbit version of the learning world". Frontiers in Psychology, 7, 1959. https://doi.org/10.3389/ fpsyg.2016.01959

Rubel, A., \& Jones, K. M. (2016). Student privacy in learning analytics: An information ethics perspective. The Information Society, 32(2), 143-159. https://doi.org/10.1080/01972243.2016.1130502

Schumacher, C., \& Ifenthaler, D. (2018). Features students really expect from learning analytics. Computers in Human Behavior, 78, 397-407. https://doi.org/10.1016/j.chb.2017.06.030

Sclater, N., \& Bailey, P. (2015). Code of Practice for Learning Analytics. Jisc. Retrieved from https : / / www • j i s c . ac . uk / guides/code-of-practice-for-learning-analytics

Selwyn, N. (2015). Data entry: Towards the critical study of digital data and education. Learning, Media and Technology, 40(1), 64-82. https://doi.org/10.1080/17439884.2014.921628

Selwyn, N. (2019). What's the problem with learning analytics? Journal of Learning Analytics, 6(3), 11-19. https://doi.org/ 10.18608/jla.2019.63.3

Selwyn, N. (2020). Re-imagining "learning analytics"... A case for starting again? The Internet and Higher Education, 46, 100745. https://doi.org/10.1016/j.iheduc.2020.100745

Selwyn, N., \& Gašević, D. (2020). The datafication of higher education: Discussing the promises and problems. Teaching in Higher Education, 25(4), 527-540. https://doi.org/10.1080/13562517.2019.1689388

Slade, S., \& Prinsloo, P. (2013). Learning analytics: Ethical issues and dilemmas. American Behavioral Scientist, 57(10), 1510-1529. https://doi.org/10.1177/0002764213479366

Slade, S., Prinsloo, P., \& Khalil, M. (2019). Learning analytics at the intersections of student trust, disclosure and benefit. In Proceedings of the Eighth International Conference on Learning Analytics and Knowledge (LAK 2019), 4-8 March 2019, Tempe, AZ, USA (pp. 235-244). New York: ACM. https://doi.org/10.1145/3303772.3303796

The Open University. (2014). Policy on Ethical Use of Student Data for Learning Analytics. The Open University. Retrieved from https://help.open.ac.uk/documents/policies/ethical-use-of-student-data

Thompson, K., Alhadad, S. S., Buckingham Shum, S., Howard, S., Knight, S., Martinez-Maldonado, R., \& Pardo, A. (2018). Connecting expert knowledge in the design of classroom learning experiences. In J. M. Lodge, J. C. Horvath, \& L. Corrin (Eds.), From Data and Analytics to the Classroom: Translating Learning Analytics for Teachers. Taylor \& Francis. Retrieved from http://hdl . handle.net/10453/127709

Tsai, Y.-S., \& Gašević, D. (2017). Learning analytics in higher education-Challenges and policies: A review of eight learning analytics policies. In Proceedings of the Seventh International Conference on Learning Analytics and Knowledge (LAK 2017), 13-17 March 2017, Vancouver, BC, Canada (pp. 233-242). New York: ACM. https://doi.org/10.1145/ 3027385.3027400

Tsai, Y.-S., Moreno-Marcos, P. M., Jivet, I., Scheffel, M., Tammets, K., Kollom, K., \& Gašević, D. (2018). The SHEILA framework: Informing institutional strategies and policy processes of learning analytics. Journal of Learning Analytics, 5(3), 5-20. https://doi.org/10.18608/jla.2018.53.2

Tsai, Y.-S., Perrotta, C., \& Gašević, D. (2019). Empowering learners with personalised learning approaches? Agency, equity and transparency in the context of learning analytics. Assessment \& Evaluation in Higher Education, 1-14. https://doi.org/10.1080/02602938.2019.1676396 
Tsai, Y.-S., Poquet, O., Dawson, S., Pardo, A., \& Gašević, D. (2019). Complexity leadership in learning analytics: Drivers, challenges, and opportunities. British Journal of Educational Technology, 50(6), 2839-2854. https://doi.org/10.1111/ bjet. 12846

Tsai, Y.-S., Rates, D., Moreno-Marcos, P. M., Muñoz-Merino, P. J., Jivet, I., Scheffel, M., ... Gašević, D. (2020). Learning analytics in European higher education-Trends and barriers. Computers \& Education, 103933. https://doi.org/10.1016/ j.compedu.2020.103933

Tsai, Y.-S., Whitelock-Wainwright, A., \& Gašević, D. (2020). The privacy paradox and its implications for learning analytics. In Proceedings of the 10th International Conference on Learning Analytics and Knowledge (LAK 2020), 23-27 March 2020, Frankfurt, Germany (pp. 230-239). New York: ACM. https://doi.org/10.1145/3375462.3375536

Uhl-Bien, M., \& Arena, M. (2018). Leadership for organizational adaptability: A theoretical synthesis and integrative framework. The Leadership Quarterly, 29(1), 89-104. https://doi.org/10.1016/j.leaqua.2017.12.009

Viberg, O., Hatakka, M., Bälter, O., \& Mavroudi, A. (2018). The current landscape of learning analytics in higher education. Computers in Human Behavior, 89, 98-110. https://doi.org/10.1016/j.chb.2018.07.027

Vigentini, L., Liu, D. Y., Arthars, N., \& Dollinger, M. (2020). Evaluating the scaling of a LA tool through the lens of the SHEILA framework: A comparison of two cases from tinkerers to institutional adoption. The Internet and Higher Education, 45, 100728. https://doi.org/10.1016/j.iheduc.2020.100728

Whitelock-Wainwright, A., Gašević, D., Tejeiro, R., Tsai, Y.-S., \& Bennett, K. (2019). The student expectations of learning analytics questionnaire. Journal of Computer Assisted Learning, 35(5), 633-666. https://doi.org/10.1111/jcal.12366

Williamson, B. (2018). The hidden architecture of higher education: Building a big data infrastructure for the "smarter university". International Journal of Educational Technology in Higher Education, 15(1), 12. https://doi.org/10.1186/ s41239-018-0094-1

Williamson, B., Bayne, S., \& Shay, S. (2020). The datafication of teaching in higher education: Critical issues and perspectives. Teaching in Higher Education, 25(4), 351-365. https://doi.org/10.1080/13562517.2020.1748811

Wintrup, J. (2017). Higher education's panopticon? Learning analytics, ethics and student engagement. Higher Education Policy, 30(1), 87-103. https://doi.org/10.1057/s41307-016-0030-8

Zuboff, S. (2015). Big other: Surveillance capitalism and the prospects of an information civilization. Journal of Information Technology, 30(1), 75-89. https://doi.org/10.1057/jit.2015.5 


\section{Appendices}

\subsection{Staff Questionnaire}

1. The university will provide me with guidance on how to access learning analytics about my students.

2. The university will provide me with sufficient guidance or training on how to use learning analytics to support my students and/or inform my teaching.

3. The use of learning analytics will not increase my workload.

4. The university will provide staff with opportunities for professional development in using learning analytics for teaching.

5. The university will facilitate open discussions to share experience of learning analytics services.

6. I will be able to access data about my students' progress in a course that I am teaching/tutoring.

7. I will be able to access data about any students within a programme.

8. The learning analytics service will allow students to make their own decisions based on the data they receive.

9. The university will have an explicit conduct of ethics and privacy protection policy in place for the use of learning analytics.

10. The university will provide support (e.g., advice from personal tutors) as soon as possible if the analysis of a student's educational data suggests they may be having some difficulty or problem (e.g., underperforming or at risk of failing).

11. The university will regularly update students about their learning progress based on the analysis of their educational data.

12. The learning analytics service will collect and present data that is accurate (i.e., free from inaccuracies such as incorrect grades).

13. The learning analytics service will collect and present data that is useful for my teaching purposes (e.g., patterns of student engagement with different learning materials or topics).

14. The learning analytics service will show how a student's learning progress compares to their learning goals/the course objectives.

15. The feedback from the learning analytics service will be presented in a format that is both understandable and easy to read.

16. The feedback from the learning analytics service will be used to help me improve the educational experience in a course/programme I am responsible for (e.g., identifying problems in the feedback, assessments, and learning activities).

17. The learning analytics service will present students with a complete profile of their learning across every course (e.g., number of accesses to online material, learning outcomes, and attendance).

18. The teaching staff will be competent in incorporating analytics into the feedback and support they provide to students.

19. The teaching staff will have an obligation to act (i.e., support students) if the analytics show that a student is at risk of failing or underperforming, or that they could improve their learning.

20. The feedback from the learning analytics service will be used to promote students' academic and professional skill development (e.g., essay writing and referencing) for their future employability.

21. The use of learning analytics will allow me to better understand my students' learning performance.

22. The use of learning analytics will allow me to better understand my students' use of learning strategies. 


\subsection{Student Questionnaire}

1. The university will ask for my consent before using any identifiable data about myself (e.g., ethnicity, age, and gender).

2. The university will ensure that all my educational data will be kept securely.

3. The university will ask for my consent before my educational data is outsourced for analysis by third-party companies.

4. The university will regularly update me about my learning progress based on the analysis of my educational data.

5. The university will ask for my consent to collect, use, and analyse any of my educational data (e.g., grades, attendance, and virtual learning environment accesses).

6. The university will request further consent if my educational data is being used for a purpose different to what was originally stated.

7. The learning analytics service will be used to promote student decision making (e.g., encouraging you to adjust your set learning goals based upon the feedback provided to you and draw your own conclusions from the outputs received).

8. The learning analytics service will show how my learning progress compares to my learning goals/the course objectives.

9. The learning analytics service will present me with a complete profile of my learning across every module (e.g., number of accesses to online material and attendance).

10. The teaching staff will be competent in incorporating analytics into the feedback and support they provide to me.

11. The teaching staff will have an obligation to act (i.e., support me) if the analytics show that I am at risk of failing or underperforming, or if I could improve my learning.

12. The feedback from the learning analytics service will be used to promote academic and professional skill development (e.g., essay writing and referencing) for my future employability. 


\subsection{Staff Focus Group Questions}

\begin{tabular}{|c|c|}
\hline Themes & Questions \\
\hline Purpose & $\begin{array}{l}\text { Learning analytics benefits from a range of education data, including academic } \\
\text { data, personal data, and engagement data collected from online or physical } \\
\text { learning environments. What do you think would be legitimate purposes for the } \\
\text { university to use such data? }\end{array}$ \\
\hline Teaching needs & $\begin{array}{l}\text { What kinds of data would be particularly useful to you in improving students' } \\
\text { educational experience in a module/course/programme that you are responsible } \\
\text { for? }\end{array}$ \\
\hline Teaching needs & $\begin{array}{l}\text { What kinds of data would be particularly useful to you in your professional } \\
\text { development? }\end{array}$ \\
\hline Teaching needs & $\begin{array}{l}\text { Do you see any challenges in offering teaching and learning support to your } \\
\text { students? }\end{array}$ \\
\hline Teaching needs & $\begin{array}{l}\text { Do you see any ways learning analytics could be used to address these challenges } \\
\text { by taking advantage of student data or data about your teaching performance? }\end{array}$ \\
\hline Ethics and privacy & $\begin{array}{l}\text { Do you consider there to be any ethical or legal issues concerning the use of } \\
\text { student data or data about your teaching activities and effectiveness? }\end{array}$ \\
\hline Educational support & $\begin{array}{l}\text { Here are some examples of ways the university could use learning analytics } \\
\text { to enhance learning and teaching. Which of these uses do you think would be } \\
\text { useful (multiple choices)? Please pick one to share why it is useful or not useful } \\
\text { after the poll. } \\
\text { (a) To improve the relationships between students and teaching staff or tutors } \\
\text { (b) To improve the overall learning experience and well-being of students } \\
\text { (c) To identify a student's weaknesses in learning and suggest ways to improve } \\
\text { upon this } \\
\text { (d) To alert teaching staff early if students are at risk of failing a module or if } \\
\text { they could improve their learning } \\
\text { (e) To identify the optimum pathway for students to achieve their learning goals } \\
\text { (f) To present students with a complete profile of their learning in each and } \\
\text { every module } \\
\text { (g) To present teaching staff or tutors with a complete learning profile of their } \\
\text { students } \\
\text { (h) To present teaching staff or tutors with a profile of their teaching activities } \\
\text { and effectiveness. }\end{array}$ \\
\hline Intervention & $\begin{array}{l}\text { How do you think teaching staff and tutors should approach the analysis results } \\
\text { of student data? }\end{array}$ \\
\hline Concerns & $\begin{array}{l}\text { Are there any concerns you would have in incorporating learning analytics into } \\
\text { teaching? }\end{array}$ \\
\hline Final remarks & $\begin{array}{l}\text { Do you have any suggestions for the adoption of learning analytics at the } \\
\text { university? }\end{array}$ \\
\hline
\end{tabular}




\subsection{Student Focus Group Questions}

\begin{tabular}{|c|c|}
\hline Themes & Questions \\
\hline Transparency & $\begin{array}{l}\text { Are you aware that your university has the ability to collect and analyse data } \\
\text { about your actions in various learning environments (e.g., virtual learning } \\
\text { environments, lecture attendance, library accesses)? }\end{array}$ \\
\hline Purpose & What would be legitimate purposes for the university to use your data? \\
\hline Consent and ownership & $\begin{array}{l}\text { Do you consider there to be any ethical or legal issues with this collection and } \\
\text { analysis of your data? }\end{array}$ \\
\hline Autonomy & $\begin{array}{l}\text { Do you think the university should allow you to opt out of data collection at any } \\
\text { time? }\end{array}$ \\
\hline Educational needs & $\begin{array}{l}\text { Thinking about the learning support that you have received from the university, } \\
\text { is there anything that could have been done better? }\end{array}$ \\
\hline Educational needs & $\begin{array}{l}\text { Would you like the university to use your background and educational data to } \\
\text { support you in areas that we just discussed? }\end{array}$ \\
\hline Educational needs & $\begin{array}{l}\text { Here are some examples of ways the university could use your background and } \\
\text { educational data to support your learning. Which of these uses of your data } \\
\text { would you prefer? Please pick one to share why it is useful or not useful after } \\
\text { the poll. } \\
\text { (a) To improve your relationships with teaching staff or tutors } \\
\text { (b) To improve your overall learning experience and well-being } \\
\text { (c) To identify weaknesses in your learning and suggest ways to improve upon } \\
\text { this } \\
\text { (d) To alert teaching staff early if you are at risk of failing a module or if you } \\
\text { could improve your learning } \\
\text { (e) To identify the optimum pathway through your studies } \\
\text { (f) To present you with a complete profile of your learning in each and every } \\
\text { module }\end{array}$ \\
\hline Feedback & $\begin{array}{l}\text { How would you like to receive feedback from the analysis of your educational } \\
\text { data? }\end{array}$ \\
\hline Interv & How should teaching staff and tutors approach the analysis of your data? \\
\hline Concerns & $\begin{array}{l}\text { Are there any concerns you would have towards the way the university uses } \\
\text { your data? }\end{array}$ \\
\hline
\end{tabular}


7.5 Differences between Ideal and Predicted Expectations

7.5.1 Staff Survey

\begin{tabular}{|c|c|c|c|}
\hline Expectations & $\begin{array}{c}\text { Ideal } \\
(\mathbf{M})\end{array}$ & $\begin{array}{c}\text { Pred. } \\
(\mathbf{M})\end{array}$ & Paired t-test \\
\hline Guidance on accessing LA about students & 5.49 & 5.05 & $t(80)=1.92, p=0.058698191, d=0.28$ \\
\hline Guidance on using LA to support students and teaching & 5.72 & 4.54 & $t(80)=6.49, p=6.63 e-09 d=0.81$ \\
\hline LA will not increase my workload & 5.15 & 2.70 & $t(80)=7.19, p=2.99 e-10, d=1.21$ \\
\hline Professional development in using LA for teaching & 5.20 & 4.51 & $t(80)=3.24, p=.001749386, d=0.44$ \\
\hline The university will facilitate open discussions & 5.48 & 4.43 & $t(80)=4.60, p=1.59 e-05, d=0.70$ \\
\hline Access data about my students' progress in a course & 5.73 & 5.04 & $t(80)=3.51, p=7.37 e-04, d=0.48$ \\
\hline Access data about any students within a programme & 4.98 & 4.40 & $t(80)=3.06, p=0.003054953, d=0.37$ \\
\hline Allow students to make their own decisions & 4.99 & 3.57 & $t(80)=7.35, p=1.49 e-10, d=0.94$ \\
\hline Have ethics and privacy protection policy in place & 6.41 & 5.74 & $t(80)=4.22, p=6.49 e-05, d=0.58$ \\
\hline The university will support struggling students & 5.33 & 4.28 & $t(80)=4.86, p=5.69 e-06, d=0.67$ \\
\hline Update students about their learning progress & 4.84 & 4.44 & $t(80)=1.98, p=0.050871637, d=0.26$ \\
\hline LA will collect and present data that is accurate & 5.91 & 4.01 & $t(80)=9.26, p=2.72 e-14, d=1.26$ \\
\hline LA will collect and present data useful for teaching & 5.31 & 3.98 & $t(80)=6.61, p=4.02 e-09, d=0.90$ \\
\hline Compare learning progress to goals/course objectives & 4.90 & 3.72 & $t(80)=6.29, p=1.59 e-08, d=0.78$ \\
\hline LA feedback will be understandable and easy to read & 5.79 & 3.95 & $t(80)=9.62, p=5.33 e-15, d=1.20$ \\
\hline Improve teaching experience in a course/programme & 5.23 & 3.86 & $t(80)=7.36, p=1.46 e-10, d=0.85$ \\
\hline Present students with a complete profile & 4.69 & 4.05 & $t(80)=3.78, p=2.98 e-04, d=0.44$ \\
\hline Staff will have the required knowledge/skills to use LA & 5.01 & 3.49 & $t(80)=7.76, p=2.40 e-11, d=0.96$ \\
\hline Staff will have an obligation to act on LA & 3.65 & 4.23 & $t(80)=-2.45, p=0.016505632, d=0.33$ \\
\hline Promote students' academic and professional skills & 4.75 & 3.94 & $t(80)=4.13, p=8.85 e-5, d=0.61$ \\
\hline Better understand my students' learning performance & 4.86 & 3.86 & $t(80)=6.32, p=1.36 e-8, d=0.64$ \\
\hline Better understand my students' learning strategies & 4.69 & 3.79 & $t(80)=5.61, p=2.80 e-74, d=0.55$ \\
\hline
\end{tabular}

\subsubsection{Student survey}

\begin{tabular}{|c|c|c|c|}
\hline Expectations & $\begin{array}{c}\text { Ideal } \\
(\mathbf{M})\end{array}$ & $\begin{array}{c}\text { Pred. } \\
\text { (M) }\end{array}$ & Paired t-test \\
\hline Seek consent before using identifiable data & 6.32 & 5.86 & $t(673)=8.94, p=3.65 e-18, d=0.37$ \\
\hline My data will be kept securely & 6.58 & 6.05 & $t(673)=11.16, p=1.16 e-26, d=0.48$ \\
\hline Seek consent if educational data is outsourced & 6.52 & 5.66 & $t(673)=14.01, p=2.51 e-39, d=0.62$ \\
\hline Regularly update me about my learning progress & 5.59 & 4.84 & $t(673)=12.04, p=2.22 e-30, d=0.52$ \\
\hline Seek my consent before using educational data & 6.12 & 5.37 & $t(673)=13.18, p=1.97 e-35, d=0.52$ \\
\hline Seek consent if data is used for alternative purposes & 6.46 & 5.65 & $t(673)=13.84, p=1.67 e-38, d=0.61$ \\
\hline LA will promote student decision making & 5.69 & 5.07 & $t(673)=11.75, p=3.82 e-29, d=0.46$ \\
\hline Compare my progress with goals/course objectives & 5.68 & 5.09 & $t(673)=11.09, p=2.26 e-26, d=0.43$ \\
\hline Present a complete profile of my learning & 5.59 & 5.00 & $t(673)=10.63, p=1.72 e-24, d=0.42$ \\
\hline Staff will be competent in incorporating LA & 5.74 & 4.54 & $t(673)=17.37, p=3.98 e-56, d=0.77$ \\
\hline The teaching staff will have an obligation to act & 5.56 & 4.75 & $t(673)=12.43, p=4.49 e-32, d=0.49$ \\
\hline LA will promote my academic and professional skills & 5.62 & 4.93 & $t(673)=12.64, p=5.34 e-33, d=0.47$ \\
\hline
\end{tabular}

$\mathrm{CI}=95 \%$ 